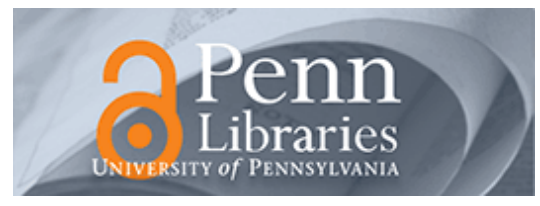

University of Pennsylvania

ScholarlyCommons

Finance Papers

Wharton Faculty Research

2014

\title{
Financial Valuation of PBGC Insurance with Market-Implied Default Probabilities
}

Jules $\mathrm{H}$. van Binsbergen

University of Pennsylvania

Robert Novy-Marx

University of Rochester

Joshua Rauh

Stanford University

Follow this and additional works at: https://repository.upenn.edu/fnce_papers

Part of the Finance and Financial Management Commons, Insurance Commons, and the Taxation Commons

\section{Recommended Citation}

Binsbergen, J. v., Novy-Marx, R., \& Rauh, J. (2014). Financial Valuation of PBGC Insurance with MarketImplied Default Probabilities. Tax Policy and the Economy, 28 (1), 133-154. http://dx.doi.org/10.1086/ 675590

At the time of publication, author Jules $\mathrm{H}$. van Binsbergen was affiliated with Stanford University. Currently, he is a faculty member at the Finance Department of the Wharton School at the University of Pennsylvania.

This paper is posted at ScholarlyCommons. https://repository.upenn.edu/fnce_papers/234

For more information, please contact repository@pobox.upenn.edu. 


\title{
Financial Valuation of PBGC Insurance with Market-Implied Default Probabilities
}

\begin{abstract}
In this paper, we use financial valuation techniques to measure the unfunded liabilities associated with the Pension Benefit Guaranty Corporation (PBGC) single-employer pension insurance program. This is an alternative approach to the calculations of expected future PBGC payouts in the PBGC exposure reports. The PBGC insurance is akin to an exchange option, a financial instrument that allows a party to exchange one risky asset for another. Calculating the value of this option for each PBGC-covered plan provides a measure of the fair market price of the PBGC guarantee that is consistent with the finance principles of risk-neutral pricing. That is, the market valuation method reflects the fact that bad outcomes tend to coincide with times when losses are particularly painful. The valuation we perform also reflects the fact that PBGC insurance is triggered only in the case of bankruptcy by drawing on the default probabilities implied by the credit ratings of insured plans. Under the baseline parameters, the PBGC's insurance of the unfunded liabilities has a financial value of $\$ 358$ billion, net of the estimated present value of PBGC premiums.
\end{abstract}

\section{Keywords}

Pension insurance; Pension Benefit Guaranty Corporation; pension liabilities; liability valuation; option pricing of government liabilities

Disciplines

Finance and Financial Management | Insurance | Taxation

\section{Comments}

At the time of publication, author Jules $\mathrm{H}$. van Binsbergen was affiliated with Stanford University. Currently, he is a faculty member at the Finance Department of the Wharton School at the University of Pennsylvania. 


\title{
Financial Valuation of PBGC Insurance with Market-Implied Default Probabilities
}

\author{
Jules H. van Binsbergen, Stanford Graduate School of Business and NBER \\ Robert Novy-Marx, University of Rochester and NBER \\ Joshua Rauh, Stanford Graduate School of Business, Hoover Institution, and NBER
}

Keywords: Pension insurance, Pension Benefit Guaranty Corporation, pension liabilities, liability valuation, option pricing of government liabilities.

\section{Executive Summary}

In this paper, we use financial valuation techniques to measure the unfunded liabilities associated with the Pension Benefit Guaranty Corporation (PBGC) single-employer pension insurance program. This is an alternative approach to the calculations of expected future PBGC payouts in the PBGC exposure reports. The PBGC insurance is akin to an exchange option, a financial instrument that allows a party to exchange one risky asset for another. Calculating the value of this option for each PBGC-covered plan provides a measure of the fair market price of the PBGC guarantee that is consistent with the finance principles of riskneutral pricing. That is, the market valuation method reflects the fact that bad outcomes tend to coincide with times when losses are particularly painful. The valuation we perform also reflects the fact that PBGC insurance is triggered only in the case of bankruptcy by drawing on the default probabilities implied by the credit ratings of insured plans. Under the baseline parameters, the PBGC's insurance of the unfunded liabilities has a financial value of $\$ 358$ billion, net of the estimated present value of PBGC premiums.

\section{Introduction}

It has long been recognized that the pricing of PBGC insurance can be viewed as a financial option (Sharpe 1976; Merton 1977; Treynor 1977). 
Firms in bankruptcy have the right to put their pension liabilities and assets to the PBGC, with the PBGC's remaining claim on the firm having the priority of an unsecured creditor. Following this recognition, there have been several empirical attempts to use options pricing models to price these guarantees on a plan-by-plan basis (Marcus 1987; Pennachi and Lewis 1994; Kiska, Lucas, and Phaup 2005).

One key challenge in applying option pricing techniques to value PBGC insurance is modeling bankruptcy. The existing options pricing techniques have modeled the sponsoring firm assets as well as the pension fund assets as a stochastic process. That is, they have specified how the sponsoring firm's operating assets and liabilities would grow if its returns followed lognormal distributions. Those assumptions, however, are often inconsistent with data in the market. Credit spreads on corporate debt of different maturities contain information about the premium that market participants must receive in order to hold corporate bonds. This premium depends on the probability of default (or bankruptcy), the market's estimation of the extent of debt recovery in default, and the state of the world in which bankruptcy of the firm is likely to occur.

A second important challenge is specifying the growth rate of liabilities, and the rates at which assets grow due to contributions and benefit payments. The previous literature has simply assumed a given baseline level of growth of pension benefits. The available plan-level data, however, provide information about the rates at which benefits are paid and new benefits accrue, relative to liabilities, for each plan. The data also provide information about the contribution rate and rate at which benefits are paid, relative to assets, for each plan.

In a sample of pension plans that represent $90 \%$ of the universe of single-employer defined benefit (DB) pension liabilities in the Internal Revenue Service (IRS) 5500 filings, we first reevaluate the current unfunded liabilities of plans covered by the PBGC using Treasury discount rates. We then use the concept of an exchange option, which allows one party to exchange one risky asset for another, to apply a risk-neutral pricing methodology and derive the value of PBGC insurance. From a taxpayer perspective, this value can be seen as the dollar equivalent that one would have to pay to a private insurance company to receive nondefaultable guarantees (Brown 2008). In contrast to options pricing approaches in the past literature, our valuation of the PBGC insurance is consistent with each plan's market-implied default probability, as well as plan level data on each plan's actual accrual rates of new benefits. 
The approach we take is different from that in the PBGC exposure reports, which are based on the Pension Insurance Modeling System (PIMS) model. The financial valuation we perform measures the market value of expected future payoffs. That is, it provides an estimate of what a very large financial market participant or very large insurer might have to be paid to take over the entire liability from the PBGC. The PIMS model does not actually value future payoffs, but rather calculates expected future payoffs. Taking expected values is not a valuation of the future payoffs, since it ignores the fact that liabilities are likely to come in states of the world where the marginal value of a dollar is high. The two methods therefore answer different questions: the calculations we produce here give a financial valuation of the liability as opposed to a measure of expected future payouts.

Even though officially the PBGC is, by statute, supposed to be selffinancing and therefore does not officially receive the full backing of the US government (Brown 2008), most observers start with the assumption that the US Congress will not let the PBGC fail. This will be the maintained assumption in this paper when we compute the liability of the PBGC to the US taxpayer.

\section{Methodology}

Methods such as those in the PIMS exposure report that consider the expected value of future PBGC payouts tell us the average payouts over all states of the world. However, the expected value of future PBGC payouts does not reflect the present value of unfunded government liabilities. That is because a present value of PBGC payouts does not take into account state pricing. The payouts that the government will have to make are likely to come in situations, or states of the world, where funds are scarce and the shadow cost of a dollar is high. That means that a financial market participant or an insurance company would have to be paid more than the simple average payout to take over the insurance from the government.

To take a very simple example, consider a stock market currently valued at $\$ 100$ with only two states of the world: an "up" state where the market returns $\$ 126$ (a positive return of $26 \%$ ) or a "down" state where the market returns $\$ 86$ (a negative return of $14 \%$ ), each of which occur with a probability of $50 \%$. This stock market has a market risk premium of $0.5^{*} 26 \%+0.5^{*}(-14 \%)=6 \%$, not far from what surveys of professional economists and chief financial officers (CFOs) today believe that the 
market risk premium should be (Graham and Harvey 2013) and a volatility of $20 \%$. There is a risk-free rate of $r_{f}=0$.

Now consider a world with a zero interest rate with an option-like derivative contract that pays $\$ 100^{*} \max \left(0,-r_{m}\right)$, that is, in finance this is what is called an at-the-money put on the market, because the strike price of the option equals the current value. The payoff of the option in the up state would be $\$ 0$, and the payoff in the down state would be $\$ 14$. If we took the expected payoff of this option, it would be $0.5^{*} 0+$ $(1-0.5)^{*} \$ 14=\$ 7$.

However, this expected payoff far understates the value of the option. If this option were to only cost $\$ 7$, an individual could earn arbitrage profits through the correct combination of borrowing and investing in the asset and in the option. Suppose that one borrows $\$ 44.10$ and uses the proceeds to invest $\$ 35$ in the stock market, buy the option for $\$ 7$, and invest the remainder of $\$ 2.10$ in the risk-free rate. If the up state realizes, the stock market investment is worth $\$ 35^{*} 1.26=\$ 44.10$ that can be used to pay back the loan (recall that the interest rate is zero), the option is worthless and one can walk away with a profit of $\$ 2.10$. If the down state realizes, the stock market investment is worth $\$ 30.10$, the option pays off $\$ 14$, for a total of $\$ 44.10$ which again can be used to pay off the loan, and allows the investor to walk away with a profit of $\$ 2.10$. That is, a risk-free profit of $\$ 2.10$ can now be made. This example illustrates that the option price of $\$ 7$ is $\$ 2.10$ too cheap. If the option price had been $\$ 7+\$ 2.10=\$ 9.10$, no arbitrage profits could be made from this investment strategy.

To formalize this, from Cox, Ross, and Rubinstein (1979), we know that the price of the option in this binomial world can be calculated as:

$$
\frac{1}{1+r}\left[\left(\frac{r-d}{u-d}\right) * 0+\left(\frac{u-r}{u-d}\right) * 14\right]
$$

where $r$ is the risk-free rate, $u$ is the return in the up state, and $d$ is the return in the down state. For $r=0, u=+26 \%$, and $d=-14 \%$, this formula indeed leads to a value of the option equal to $\$ 9.10$, or around $30 \%$ higher than the expected value of the payoffs. The terms $(r-d) /(u-d)$ and $(u-r) /(u-d)$ are known as the risk-neutral probabilities of the up and down state.

The above method stands in contrast to the PBGC PIMS approach in which assets are projected forward at expected returns and then discounted back at risk-free rates. Specifically, the 2012 annual exposure report states: 
Throughout this report, we express all future outcomes in present value terms (i.e., discounted back to 2012). Each scenario's outcomes are discounted based on the 30-year Treasury bond yields projected for that scenario, regardless of whether the underlying simulated cash flows are generated from holdings of equities, highyield bonds, corporate bonds, or US Treasury bonds. (exposure report, page 15)

For an actual financial valuation, the PBGC would have to project forward scenarios based on the risk-neutral distribution of return outcomes. The mean of that distribution is the risk-free rate. One approach to obtaining a financial valuation would therefore be to project forward the assets not at their expected return but rather at a risk-free rate.

We take an approach here that in essence does just that, but also reflects that the PBGC insurance is an exchange option. Exchange options, also known as outperformance options, pay off only if the underlying asset outperforms some other asset (McDonald 2003). In the case of a pension system, the idea is that the PBGC insurance only has value in states of the world where the stochastically evolving liabilities exceed the stochastically evolving assets. The PBGC is giving firms the option to put their assets in exchange for the defeasance value of the liabilities. ${ }^{1}$

Let the assets of the pension plan be denoted by $A_{t}$ and the liabilities by $L_{t}$. Assets are influenced by investment choices of the plan as well as inflows from the plan sponsor and outflows to pension holders. Liabilities are influenced by interest rate fluctuations, demographic changes, indexation rules, and so forth. Further, let the funding ratio be given by:

$$
\Phi_{t}=\frac{A_{t}}{L_{t}}
$$

As a simplistic starting point, assume that the annual log volatility of the growth of assets of the pension plan is given by $\sigma_{A}$, and that the volatility of the log growth of liabilities is given by $\sigma_{L}$. Further, let the correlation between the assets and the volatilities be given by $\rho_{A L}$. The volatility of the log funding ratio is then given by:

$$
\sigma=\sqrt{\sigma_{A}^{2}+\sigma_{L}^{2}-2 \rho_{A L} \sigma_{A} \sigma_{L}}
$$

So if the pension plan could fully hedge changes in liabilities by appropriately choosing their investment policy, then $\sigma=0$.

\section{A. A Simplified Example: Random Default and Proportional Insurance}

Now suppose that a firm defaults with a default intensity $\lambda$, that default is unrelated to fluctuations in the asset-liability ratio $\Phi_{t}$, that the firm's 
pension liabilities are fixed, and that new benefits accrue outside the pension plan. We will relax these assumptions in a moment. Further assume that the PBGC's insurance only kicks in when the asset liability ratio is below a fraction $K$ total liabilities. So if assets are $80 \%$ of liabilities and $\mathrm{K}=0.9$, then the PBGC is only on the hook for $10 \%$ of the liabilities. This is to represent the fact that the PBGC is only liable for pension promises up to a certain annual cap. In 2013 the cap was $\$ 57,477$ per year for a 65 -year-old retiree. The covered amount is higher for older retirees, but lower for those who retire early or choose survivor benefits.

In that case, the Black-Scholes value of the put option the PBGC has implicitly written on the firm's pension liabilities (as a fraction of the total liabilities) is equal to:

$$
V_{P B G C}=\int_{t}^{\infty} f(\lambda, s) p(s) d s,
$$

where:

$$
\begin{gathered}
p(s)=e^{-r(s-t)} K N\left(-d_{2}\right)-\Phi_{t} N\left(-d_{1}\right) \\
d_{1}=\frac{\ln \left(\frac{\Phi_{t}}{K}\right)+\left(r+\frac{\sigma^{2}}{2}\right)(s-t)}{\sigma \sqrt{s-t}} \\
d_{2}=d_{1}-\sigma \sqrt{s-t}
\end{gathered}
$$

The function $f(\lambda, s)$ describes the risk-neutral probability of defaulting at time $s$. We use credit spread data by credit rating to calibrate firmspecific risk-neutral default probabilities by horizon. We assume that the sponsor's default is uncorrelated with the evolution of the funding ratio. In practice, default is more likely in bad economic times when stock markets perform poorly and interest rates are low. An analysis that accounted for this would raise the value of the insurance above the values that we report. As such, our estimates are conservative.

\section{B. Exchange Option}

One only needs to reexpress the above formulas to derive the price of the exchange option. Multiplying $p(s)$ by $L_{t}$ (i.e., switching back to dollars for the numeraire), and recognizing $F_{t, t+s}^{L}=L_{t} / B_{t, t+s}$ and $F_{t, t+s}^{A}=A_{t} / B_{t, t+s}$ are the s-period ahead forward prices of $L_{t}$ and $A_{t}$, respectively, we have that 


$$
\begin{gathered}
p(s)=B_{t, t+s}\left[K F_{t, t+s}^{L} N\left(-d_{2}\right)-F_{t, t+s}^{A} N\left(-d_{1}\right)\right] \\
d_{1}=\frac{\ln F_{t, t+s}^{A}-\ln \left(K F_{t, t+s}^{L}\right)+\frac{\sigma^{2}}{2}(s-t)}{\sigma \sqrt{s-t}} \\
d_{2}=d_{1}-\sigma \sqrt{s-t}
\end{gathered}
$$

where $B_{t, t+s}$ is the time $t$ price of a dollar that is paid out at time $t+s$, and where we have implicitly assumed that the natural growth rates of assets and liabilities are the same under the risk-neutral measure. This formulation is also much more general. It applies to the case with stochastic liabilities, new contributions, new benefit accruals, and benefit payments made out of plan assets, provided the forward prices of the assets and the liabilities account for the inflows and outflows resulting from contributions, new accruals, and payments made to retirees.

The current market value of the liabilities' defeasance portfolio $\left(L_{t}\right)$ is obviously an important input to the pricing model. Current rules do not, however, require plans to report this number, or even their forecasts of the annual benefits they expect to pay. We must infer this number, therefore, from what plans do report, a summary discounted "value" of these liabilities, and the capitalization rate (the "effective interest rate") that they employ in this calculation. We calculate the market value of the defeasance portfolio for the pension promises (a portfolio of treasuries that have the same cash flows) by "undiscounting" the reported pension liability at the reported effective discount rate, and rediscounting at Treasury rates. Doing so requires an assumption regarding the duration of plans' pension liabilities, and we consider three possible scenarios: a baseline assumption of 15 years, which is a number typically assumed in the pension industry, and low and high scenarios assuming 12 and 18 year liability durations, respectively.

In summary, to implement the exchange-options framework described above we need the following set of inputs: the current value of the liabilities, the current value of the assets, the probability of default by horizon adjusted for the comovement with the economy (also called the risk-neutral probability of default), the volatility of assets and liabilities, as well as their correlation.

\section{Sample}

The universe of plans on the Employee Benefits Security Administration (EBSA) plan data website was downloaded for years 2010 and 
2011. To obtain the sample, we sorted the plans from largest to smallest total liabilities as of the year 2010, and included the largest plans by total liabilities, so that $90 \%$ of total liabilities were included. This leads to a sample of 1,601 plans. This sample was selected to avoid having to clean the entire IRS 5500 database of plans. If the plans representing the remaining $10 \%$ of liabilities are similar to the remaining plans, then the results for the universe can be obtained by dividing the results for the sample by 0.9 .

\section{Implementation and Discussion}

There are two particular papers in previous literature that are similar to our approach. Marcus (1987) essentially considers the PBGC's liability as that of a long position in a forward contract on the pension fund assets, with an exercise price equal to fund liabilities and a stochastic maturity date. In that exercise, the PBGC still obtains the surplus in an overfunded plan. The firm's debt and value evolve according to stochastic equations of motion, and when the value of the debt falls below the value of the assets, bankruptcy is triggered. Pennachi and Lewis (1994) tackle the fact that in practice, the PBGC does not access overfunded plan assets by using put option pricing, but continues to use stochastic equations of motion for firm debt and firm assets to model bankruptcy. These papers also make parametric assumptions about benefit accrual and contributions.

The major departures we take from this literature are twofold. First, we calibrate benefit accruals and contributions directly to plan-level information. We assume that for the next 10 years the rates at which benefits are paid and new benefits accrue, relative to liabilities, and that the contribution rate and rate at which benefits are paid, relative to assets, are the firm-specific values we observe in the data. We assume that beyond 10 years these rates revert to the observed crosssectional mean.

Second, we use the default rates that are implied by the credit ratings of the plans in question. To perform this step, we first collected credit ratings for all of the plans that we could match to the Compustat annual file on publicly traded firms by name or employer identification number (EIN). This resulted in ratings for 768 of the 1,601 firms. We assigned numerical ratings categories of 1 for AAA, 2 for $\mathrm{AA}+, 3$ for AA, and so on. For those firms we ran the following regression: 


$$
\begin{aligned}
\text { Numerical }+ \text { Rating }= & \propto+\beta_{1} \frac{\text { Retired }}{\text { Active }}+\beta_{2} \frac{\text { Assets }}{\text { Liabilities }} \\
& +\beta_{3} \ln \text { (Liabilities) }+\varepsilon
\end{aligned}
$$

for which complete information on the explanatory variables were available for 768 firms. For the remaining firms, we assigned imputed values based on the coefficients in this regression, all of which were statistically significant at the $5 \%$ level at least. ${ }^{2}$

Figure 1 shows the distributions of credit ratings in both the sample of plans sponsored by rated firms and in the complete sample that includes all imputations. The top figure shows counts, where the total count of the plans sponsored by rated firms amounts to 768, and the total count of all rated and sponsored firms is $1,600 .^{3}$ The bottom figure shows the frequency distribution of the credit ratings, both the actual ratings of the rated firms and in the full sample that includes the imputations. From this figure it can be seen that much of the mass of the plans actually belonging to rated sponsors is in the $\mathrm{BBB}-$ to $\mathrm{A}$ range. The imputation adds the most firms to the $\mathrm{BBB}, \mathrm{BBB}-$, and $\mathrm{BB}+$ brackets of the histogram.

For each rating class, we have collected recent data on credit spreads. Using imputed credit ratings for each firm, we can then use the credit spreads to uncover the risk-neutral intensity of default. Let $\mathrm{cs}_{i}$ denote the credit spread for rating category $i$, and let $\kappa_{i}$ denote the recovery rate of rating category $I$; then the average default intensity $\lambda_{i}$ is simply given by:

$$
\lambda_{i}=\frac{C S_{i}}{1-\kappa_{i}}
$$

As we discussed above, the PIMS model projects assets forward at expected returns and discounts the net position back at risk-free rate, to measure today's expectation of the future surplus. A modification to the PIMS model that would make it more analogous to the option methodology would be instead to project assets forward using the risk-free rate as the asset's expected growth rate, but maintaining the weights on the different possible outcomes. This is equivalent to projecting asset growth using its actual expected rate of return, but reducing the weights of the good outcomes and increasing the weights on the bad outcomes, that is, using the risk-neutral probabilities rather than the objective probabilities for the outcomes.

The options pricing techniques are derived from the Black-Scholes options pricing formula. The basic underlying assumption here is that 

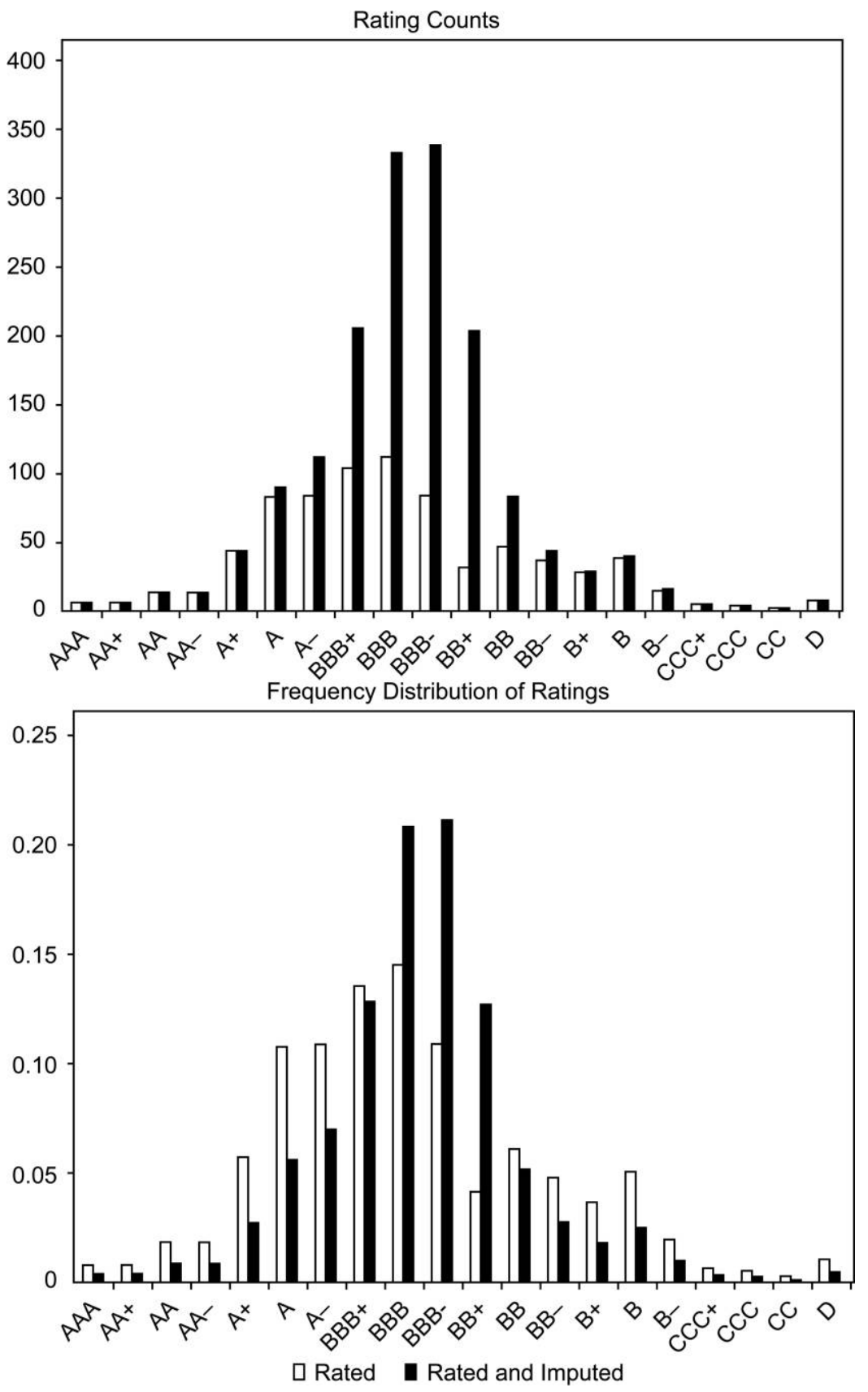

Fig. 1. Distribution of credit ratings 
liabilities could be defeased, or matched, using different combinations of marketable securities. Our analysis treats the replicating portfolio of the liabilities, the constituent pieces of which are traded, as the liabilities. As such, the risk-neutral natural growth rate of liabilities is the riskfree rate.

The variances and correlations between each of the asset classes are computed using monthly return data between March 2000 and December 2012. For stocks we use dollar denominated returns on the Morgan Stanley Capital International (MSCI) world index. For bonds, we use zero coupon bond returns with a constant maturity of 10 years. For real estate, we use changes in the Case Shiller house price index. We then annualize these estimates to arrive at the actual parameters we use in our simulations.

By using firm-specific data on portfolio holdings and combining these with the variance-covariance matrix of the asset classes, we can compute the volatility of assets as well as the correlation between assets and liabilities. The portfolio holdings data for the pension plans come from the $10-\mathrm{K}$ filings of the publicly traded companies in our sample, which we match by hand to the IRS 5500 filings in the sample by employer identification number (EIN) and where applicable by name. This matching covers only $40 \%$ of the sample. Where plans are not matched to the 10-Ks, specifically in the instance of the plans of privately held companies, we use the sample average.

The dynamics of liabilities are mostly driven by variation in longterm interest rates. As such, long-term bonds are the best hedge against fluctuations in the liabilities. Put differently, the risk-free asset for a pension plan is long-term bonds, not cash. If long-term bonds and stocks are highly positively correlated, stocks are a good hedge against liability risk. If long-term bonds and stocks have a low (or even a negative) correlation, stocks are a poor liability hedge. Unfortunately, the latter is what is suggested by the data. In our simulations, a plan that chooses to invest heavily in stocks will have a poor hedge against liability risk, which increases the volatility of the funding ratio and makes the PBGC put more valuable to the plan, and more costly to the PBGC.

Table 1 shows the parameters we use in the model. These parameters are: the volatilities of stocks, bonds, and real estate; the correlations among these different asset classes; the duration of the liabilities; and the percent of liabilities covered by the PBGC insurance. Note that with precise enough data about plan liabilities, it would be possible to calculate precise durations for each plan, as well as relatively accurate 
Table 1

Model Ingredients

\begin{tabular}{ll}
\hline Parameter & Baseline (Scenarios) \\
\hline$\sigma($ equity) & $16.6 \%$ \\
$\sigma(10 y r$ bond $)$ & $10.2 \%$ \\
$\sigma($ real estate) & $3.9 \%$ (alternative: $\sigma($ equity) $)$ \\
$\rho(10 y r$ bond, equity) & -0.317 (alternative: 0$)$ \\
$\rho($ real estate, equity) & 0.090 \\
$\rho($ real estate, 10yr bond) & 0.003 \\
Duration of liabilities & 15 years $(12$ years, 18 years) \\
$\%$ of Liabilities covered & $90 \%(80 \%, 100 \%)$ \\
\hline
\end{tabular}

Note: All bonds referred to here are zero coupon.

Table 2

Sample Summary Statistics (2010/2011), N = 1,601 Plans

\begin{tabular}{lccc}
\hline Variable & Mean & Median & Standard Deviation \\
\hline Liabilities (\$ billions) & 1.083 & 0.426 & 2.727 \\
Assets ( $\$$ billions) & 1.096 & 0.415 & 2.818 \\
Effective interest rate & $6.9 \%$ & $7.0 \%$ & $0.4 \%$ \\
Benefits / Assets & 0.064 & 0.064 & 0.031 \\
Benefits / Liabilities & 0.060 & 0.061 & 0.030 \\
Normal cost / Liabilities & 0.027 & 0.027 & 0.021 \\
\hline
\end{tabular}

Note: Values for 2011 are used when available ( $88 \%$ of the sample), else values for 2010.

estimates of the percent of each plan's liabilities covered by the PBGC. Table 2 shows several summary statistics for 1,601 plans in our sample.

\section{Results}

Table 3 shows the results of adjusting pension liabilities reported by the plans themselves on the IRS 5500 filings to reflect their value as default-free government promises. When plans are taken over by the government, they effectively become default-free government obligations, and as such, it is important to understand the value of total liabilities as a preface to measuring the PBGC insurance value.

Panel A of table 3 presents the present values. The total liability in the sample at the segment rates is $\$ 1.736$ trillion. Dividing that total by 0.9 results in the estimated total universe liability of $\$ 1.929$ trillion. But plans calculate these liabilities using the IRS segments rates, the averages of which are presented in panel B for 2010 and 2011. The segment rates are based on averages of corporate bonds for short-term, 
Table 3

Adjusting Pension Liabilities to Treasury Discount Rates

\begin{tabular}{lcccc}
\hline Panel A: Pension Liability Under Different Yield Curves, $\$$ trillions & \\
\hline Rate & Duration & $\begin{array}{c}\text { Total Liability } \\
\text { (Sample) }\end{array}$ & $\begin{array}{c}\text { Total Liability } \\
\text { (Universe) }\end{array}$ & $\begin{array}{c}\text { Total Funding } \\
\text { Status (Universe) }\end{array}$ \\
\hline $\begin{array}{l}\text { Segment rates } \\
\text { (Stated in 5500s) }\end{array}$ & $\mathrm{NA}$ & $\$ 1.736$ & $\$ 1.929$ & \\
\hline $\begin{array}{l}\text { Treasury } \\
\text { Treasury } \\
\text { Treasury }\end{array}$ & $12 \mathrm{yr}$ & $\$ 2.611$ & $\$ 2.901$ & 0.020 \\
\hline
\end{tabular}

Panel B: Average Segment Rates Employed by Sample Plans

\begin{tabular}{ccccc}
\hline & $\begin{array}{c}\text { 1st Segment } \\
<5 \text { years }\end{array}$ & $\begin{array}{c}\text { 2nd Segment } \\
\text { 5-20 years }\end{array}$ & $\begin{array}{c}\text { 3rd Segment } \\
>\text { 20 years }\end{array}$ & $\begin{array}{c}\text { Overall Effective } \\
\text { Interest Rate }\end{array}$ \\
\hline 2010 & 4.77 & 6.66 & 6.77 & 6.59 \\
2011 & 3.87 & 6.19 & 7.54 & 6.18 \\
\hline
\end{tabular}

Panel C: Treasury Yield Curve, July 2013

\begin{tabular}{ccccccccc}
\hline Maturity & 1 & 2 & 3 & 5 & 7 & 10 & 20 & 30 \\
\hline Par yield & 0.11 & 0.34 & 0.66 & 1.40 & 1.97 & 2.57 & 3.30 & 3.61
\end{tabular}

Notes: Total sample assets are $\$ 1.754$ trillion, which if representing $90 \%$ of the sample would imply total single-employer universe assets of $\$ 1.949$ trillion. Panel A shows the total pension liability for the $90 \%$ sample and the estimate of the universe (sample value / 0.9) both as stated in the IRS 5500 filings and under Treasury yields of different duration. Panel B shows the average segment rates employed by the plans in calculating their stated liabilities. Panel $\mathrm{C}$ shows the par Treasury yield curve from which the zero coupon yields in Panel A are calculated.

medium-term, and long-term maturities. These segment rates are well above the yields on Treasury bonds in panel C.

We infer the zero coupon yield curve from the more easily obtainable coupon bond yields. Specifically, we employ the par yield curve for July 15, 2013, provided by the US Department of the Treasury. We get a complete set of zero coupon bond yields from zero coupon bond prices, which we get by stripping the par bonds. ${ }^{4}$ By using government bond yields as the risk-free asset, we are ignoring the so-called liquidity premium (for example, because government bonds are used as collateral in many transactions), which could make those government yields lower than the "true" yields. Given that this effect is generally small, this should not have a large effect on our results.

If the liabilities have a duration of 12 years, then moving from corporate segment rate discounting to zero coupon Treasury discounting 
Table 4

Insurance Value of PBGC Liabilities (\$ billions) Directly from Model

\begin{tabular}{llll}
\hline & \multicolumn{3}{c}{ Liability Duration } \\
\cline { 2 - 4 }$\rho($ stocks,bonds) $=0$ & 12 Years & 15 Years & 18 Years \\
\hline $\begin{array}{c}80 \% \text { Cap } \\
\kappa=0.50\end{array}$ & $\$ 123.5$ & $\$ 200.3$ & $\$ 301.5$ \\
$\kappa=0.65$ & $\$ 152.0$ & $\$ 244.8$ & $\$ 365.3$ \\
$\kappa=0.80$ & $\$ 197.1$ & $\$ 314.2$ & $\$ 462.6$ \\
$90 \%$ Cap & & & \\
$\kappa=0.50$ & $\$ 186.7$ & $\$ 282.5$ & $\$ 404.0$ \\
$\kappa=0.65$ & $\$ 230.7$ & $\$ 346.2$ & $\$ 490.6$ \\
$\kappa=0.80$ & $\$ 302.2$ & $\$ 447.2$ & $\$ 624.4$ \\
Full Insurance & & & \\
$\kappa=0.50$ & $\$ 259.7$ & $\$ 373.7$ & $\$ 514.8$ \\
$\kappa=0.65$ & $\$ 321.6$ & $\$ 458.5$ & $\$ 625.7$ \\
$\kappa=0.80$ & $\$ 422.7$ & $\$ 593.7$ & $\$ 797.9$ \\
\hline
\end{tabular}

Notes: This table shows the insurance value of the PBGC liabilities using the exchange option methodology with ratings-specific default probabilities, under a variety of different parameters. Cap represents the percentage of total liabilities that are covered, that is, below the PBGC maximum pension limits. The parameter $\kappa$ is the recovery rate that we assume on the corporate bonds when calculating the implied risk-neutral default probability. Given a level of the credit spread, a higher recovery rate implies a higher riskneutral probability of default. The correlation between stocks and bonds is set to the baseline value of 0 . The asset volatility is set to the estimated value for each plan. The baseline scenario is highlighted.

raises the total estimated universe liability by $50 \%$, from $\$ 1.929$ trillion to $\$ 2.901$ trillion. If liabilities have a duration of 15 years, then the increase is by $67 \%$, from $\$ 1.929$ trillion to $\$ 3.215$ trillion. For a duration of 18 years, the total liability is $\$ 3.561$ trillion, an increase of $84 \%$.

The average effective annual interest rate employed by the plans when calculating their reported liability is $6.6 \%$, roughly twice as high as the Treasury rate. Assuming a duration of 12 or 18 years thus lowers or raises the market value of the defeasance portfolio by around 10\%, relative to a duration of 15 years. ${ }^{5}$ PBGC issuance is a put on plan liabilities.

Under the baseline assumption that liabilities have a duration of 15 years, the universe unfunded liability would be $\$ 3.215$ trillion liabilities $-\$ 1.949$ trillion assets $=\$ 1.27$ trillion. ${ }^{6}$

Tables 4, 5, and 6 present our main results on the value of the PBGC insurance on these unfunded liabilities, using the options pricing techniques under market-consistent assumptions about default likelihoods. These tables show the insurance value of PBGC liabilities in the sample, 
ignoring the fact that the sample represents only $90 \%$ of the universe, and also ignoring PBGC premiums. The baseline scenario uses the following five assumptions: (1) the correlation between stocks and bonds is zero; (2) the recovery value on corporate bonds is $65 \%$, based on the value-weighted average recovery rate on senior secured debt published by Moody's (Moody's (2008)); (3) the asset volatility for each plan is equal to the historical asset volatility inferred from the plans' portfolio choices; ( 4) 90\% of total liabilities are covered by the PBGC, which is based on the four largest terminations in the PBGC history, where $87 \%$ of liabilities recovered; and (5) the duration of the pension liability is assumed to be 15 years. In this scenario, which is highlighted in the box, the insurance value of the PBGC's position is $\$ 346.2$ billion. Note again that this is before we account for the present value of the single-employer premiums to the PBGC, which we do below.

Our numbers are most similar to those of Kiska, Lucas, and Phaup (2005), who also use a risk-neutral framework to calculate the market value of the PBGC guarantee. They analyze a stripped down version of the PIMS model employed by the PBGC, simulating possible paths for the value of a firm's assets and liabilities, for both its pension and its operations. They estimate a market value PBGC insurance to nonterminated plans of $\$ 118.6$ billion. At that time the Congressional Budget Office (CBO) estimated that total official liabilities of all covered defined-benefit plans on a termination basis were $\$ 1.638$ trillion, covered by $\$ 1.269$ trillion in assets, for an unfunded liability of $\$ 369$ billion. This implies that the value of the insurance was $7 \%$ of the insured liabilities, or $32 \%$ of the unfunded liability. ${ }^{7}$ These numbers are roughly consistent with the $11 \%$ of current insured liabilities, or $28 \%$ of unfunded liabilities, in our baseline calculations. ${ }^{8}$ Kiska, Lucas, and Phaup (2005) employ numbers from more than 10 years ago, a decade over which the corporate sector has experienced enormous stress. Their analysis also does not use the information about the risk-neutral term structure of default probabilities in corporate bond yields, relying instead on a structural default model.

The figure below the $\$ 346.2$ billion number shows what happens if we instead assume a recovery rate of $80 \%$ on corporate bonds. The reason this affects the results is that for a given credit spread, a higher recovery value implies a higher risk-neutral probability of default. Therefore, the insurance value increases to $\$ 447.2$ billion under this higher recovery assumption for corporate bonds. Conversely, assuming a recovery rate of $50 \%$ would lower the estimated insurance value to $\$ 282.5$ billion.

The left and right columns of the table show what happens if the du- 
ration of the liabilities is shorter or longer than 15 years. The assumed duration of the liabilities has a large effect on the value of PBGC insurance, because it has a direct material impact on the true funding status of the covered plans, as shown previously in table 3. PBGC issuance is a put on plan liabilities.

The model reducing the duration to 12 years reduces the value of the PBGC insurance by $33 \%$, from $\$ 346.2$ billion to $\$ 230.7$ billion. Increasing the duration to 18 years raises the value of the PBGC insurance by $42 \%$, from $\$ 346.2$ billion to $\$ 490.6$ billion. Due to convexity, the increase in the value (cost to taxpayers) is greater if duration is made longer than the decrease in value if the duration is made shorter. Increasing the duration of the liabilities increases the value of the option for two reasons. First, because the adjusted level of the liabilities is lower, the option is therefore further into the money. Secondly, the volatility of the liabilities goes up as the duration increases. As option values are increasing in the volatility of the underlying, this also increases the value of the option.

As noted previously, if plan-by-plan information were available on the duration of liabilities, these calculations could be done more exactly, without having to make a parametric assumption about the duration of liabilities that applies to the entire sample.

The other parameter for which we test several values in the table is the PBGC cap, which can be thought of as the strike price of the option. The PBGC cap is our term for the percentage of plan liabilities that are covered by the PBGC. Uncovered liabilities are the portion of pension payments that are above the annual yearly pension coverage maximums. Again, with sufficient plan-by-plan data, this assumption would not have to be uniform for the entire sample.

The results in the table suggest that if the other parameters are fixed at their baseline, then if the coverage were uncapped, the financial present value cost of PBGC insurance would be $32 \%$ higher than it would be under the baseline ( $\$ 458.5$ billion in the full insurance scenario versus $\$ 346.2$ billion under the baseline of a $90 \%$ cap).

Table 5 examines the sensitivity of the results to different assumptions about the correlation between equity-like financial instruments and long-term bonds. The baseline assumption used throughout table 4, and also in the middle row of each panel of table 5, is a zero correlation. However, as discussed in the previous section, the historical data point to a negative correlation between equity returns and the changes in value on bonds or other fixed streams of payments, including pension liabilities. If that is the case, then the stock investments undertaken 
Table 5

Insurance Value of PBGC Liabilities (\$ billions) Directly from Model

\begin{tabular}{llll}
\hline & \multicolumn{3}{c}{ Liability Duration } \\
\cline { 2 - 4 }$\kappa=0.65$ & 12 Years & 15 Years & 18 Years \\
\hline $\begin{array}{l}80 \% \text { Cap } \\
\rho(\text { stocks,bonds })=-0.3\end{array}$ & $\$ 169.7$ & $\$ 269.7$ & $\$ 396.6$ \\
$\rho($ stocks,bonds $)=0$ & $\$ 152.0$ & $\$ 244.8$ & $\$ 365.3$ \\
$\rho($ stocks,bonds $)=0.3$ & $\$ 133.5$ & $\$ 218.3$ & $\$ 331.6$ \\
$90 \%$ Cap & & & \\
$\rho($ stocks,bonds $)=-0.3$ & $\$ 250.3$ & $\$ 373.0$ & $\$ 523.8$ \\
$\rho($ stocks,bonds $)=0$ & $\$ 230.7$ & $\$ 346.2$ & $\$ 490.6$ \\
$\rho($ stocks,bonds $)=0.3$ & $\$ 210.2$ & $\$ 317.7$ & $\$ 454.9$ \\
Full Insurance & & & \\
$\rho($ stocks,bonds $)=-0.3$ & $\$ 342.5$ & $\$ 486.7$ & $\$ 660.2$ \\
$\rho($ stocks,bonds $)=0$ & $\$ 321.6$ & $\$ 458.5$ & $\$ 625.7$ \\
$\rho($ stocks,bonds $)=0.3$ & $\$ 299.7$ & $\$ 428.6$ & $\$ 588.7$ \\
\hline
\end{tabular}

Notes: This table shows the insurance value of the PBGC liabilities using the exchange option methodology with ratings-specific default probabilities, under a variety of different parameters. Cap represents the percentage of total liabilities that are covered, that is, below the PBGC maximum pension limits. $\rho$ (stocks,bonds) represents the correlation between the returns on US stocks and 10-year bonds, which historically has been -0.3 . The recovery rate $\kappa$ is set to the baseline value of 0.65 . The asset volatility is set to the estimated value for each plan. The baseline scenario is highlighted.

by firms are actually a negative hedge against the value of the liabilities. That is, exactly in the states of the world where the equity-type assets in the pension funds are down, the promised cash flows are the most expensive to meet. On the other hand, the literature has provided evidence that the correlation between stocks and bonds is time varying. We therefore also consider a scenario where the correlation between stocks and bonds would be positive going forward.

Reducing the correlation between stocks and bonds from zero to -0.3 raises the value of the PBGC insurance, because the states of the world where sponsor equity investments perform poorly are exactly the same states of the world where it is particularly expensive to meet the liability. Without this correlation, the value of the PBGC insurance is the baseline value of $\$ 346.2$ billion, but with the negative correlation, the value is $\$ 373.0$ billion. In other words, if there is a negative correlation between stock returns and bond returns, then the increased asset-liability mismatch would add around $8 \%$ to the value of the PBGC's insurance position. 
Table 6

Insurance Value of PBGC Liabilities (\$ billions) Directly from Model

\begin{tabular}{llll}
\hline & \multicolumn{3}{l}{ Liability Duration } \\
\cline { 2 - 4 }$\kappa=0.65, \rho$ (stocks,bonds) $=0$ & 12 Years & 15 Years & 18 Years \\
\hline $\begin{array}{l}80 \% \text { Cap } \\
0.7 \sigma\end{array}$ & $\$ 119.4$ & $\$ 197.7$ & $\$ 300.5$ \\
$\sigma$ & $\$ 152.0$ & $\$ 244.8$ & $\$ 365.3$ \\
$1.3 \sigma$ & $\$ 192.3$ & $\$ 301.3$ & $\$ 440.5$ \\
$90 \%$ Cap & & & \\
$0.7 \sigma$ & $\$ 194.4$ & $\$ 295.5$ & $\$ 422.1$ \\
$\sigma$ & $\$ 230.7$ & $\$ 346.2$ & $\$ 490.6$ \\
$1.3 \sigma$ & $\$ 275.2$ & $\$ 406.9$ & $\$ 570.2$ \\
Full Insurance & & & \\
$0.7 \sigma$ & $\$ 283.0$ & $\$ 405.5$ & $\$ 554.8$ \\
$\sigma$ & $\$ 321.6$ & $\$ 458.5$ & $\$ 625.7$ \\
$1.3 \sigma$ & $\$ 369.0$ & $\$ 522.3$ & $\$ 708.5$ \\
\hline
\end{tabular}

Notes: This table shows the insurance value of the PBGC liabilities using the exchange option methodology with ratings-specific default probabilities, under a variety of different parameters. Cap represents the percentage of total liabilities that are covered, that is, below the PBGC maximum pension limits. We investigate the sensitivity with respect to the total volatility of the funding ratio for a range of $30 \%$ above and below the estimated values. The baseline scenario is highlighted.

In table 6 we perform a general robustness analysis with respect to the total volatility of plans' funding ratios. We consider two scenarios in addition to the baseline. The first additional scenario reduces the estimated volatility of each plan's funding ratio (the ratio of assets and liabilities) by $30 \%$. The second additional scenario raises the estimated volatility of each plan's funding ratio by $30 \%$. We perform this robustness in part as a reduced way of accounting for the possibility that contributions to the plan are higher when the plan is more underfunded, and lower when the plan is overfunded. ${ }^{9}$ Such funding-status-dependent contributions will lower the total volatility of the funding ratio. Relative to our baseline scenario, lowering the volatility decreases the insurance value from $\$ 346.2$ billion to $\$ 295.5$ billion, a change of $-15 \%$.

Table 7 adjusts the numbers in table 4 to reflect the fact that the sample represents only $90 \%$ of the universe, by dividing the figures in table 4 by 0.9. It also subtracts $\$ 27$ billion as the present value of PBGC premiums from each number. We emphasize that this is only a very rough and preliminary way of incorporating PBGC premiums, based on the figures on page 10 of the 2012 PBGC exposure report, where single employer 
Table 7

Insurance Value of PBGC Liabilities (\$ billions) with Adjustments for Sample and Premiums

\begin{tabular}{lccc}
\hline & \multicolumn{3}{c}{ Liability Duration } \\
\cline { 2 - 4 } & 12 Years & 15 Years & 18 Years \\
\hline $\begin{array}{c}80 \% \text { Cap } \\
\quad=0.65\end{array}$ & $\$ 141.9$ & $\$ 245.0$ & $\$ 378.9$ \\
$\begin{array}{c}90 \% \text { Cap } \\
\quad=0.65\end{array}$ & $\$ 229.3$ & $\$ 357.7$ & $\$ 518.1$ \\
$\begin{array}{c}\text { Full Insurance } \\
\kappa=0.65\end{array}$ & $\$ 330.3$ & $\$ 482.4$ & $\$ 668.2$ \\
\hline
\end{tabular}

Notes: This table shows the insurance value of the PBGC liabilities using the exchange option methodology with ratings-specific default probabilities, under a variety of different parameters. The figures are based on table 3 but with corrections for the fact that the original sample covered only $90 \%$ of total liabilities, and for PBGC premiums, for which we assume a 2012 present value of $\$ 27$ billion. The baseline scenario is highlighted.

premiums have a present value of $\$ 27$ billion at the mean. This does not take into account the possibility that premiums might be higher in worst states of the world conditional on firms not being bankrupt, but lower in the worst states of the world in which firms are actually bankrupt. According to the PBGC exposure report, premiums would be $\$ 19$ billion at the 15th percentile, and $\$ 36$ billion at the 85th percentile.

The central number in table 7, a PBGC insurance value net of premiums of $\$ 357.7$ billion, represents our main estimate mentioned in the executive summary.

\section{Conclusions}

Under almost all scenarios, we find that the financial market value of the PBGC insurance is higher than the present value of expected payouts provided in the PBGC exposure report. For example, over a 10-year horizon, the PBGC exposure report finds a present value mean of $\$ 32.5$ billion (the average present value of FY 2022 future outcomes) and a median of $\$ 29.9$ billion, whereas the financial valuations are in the hundreds of billions of dollars. Using our baseline parameters, the unfunded liability net of premiums is $\$ 357.7$ billion, assuming that liabilities have a 15 -year duration and exactly $90 \%$ of liabilities are covered. We note that our estimate is also conservative in that we do not incorporate the PBGC's existing obligations or assets from terminations that have already occurred. 


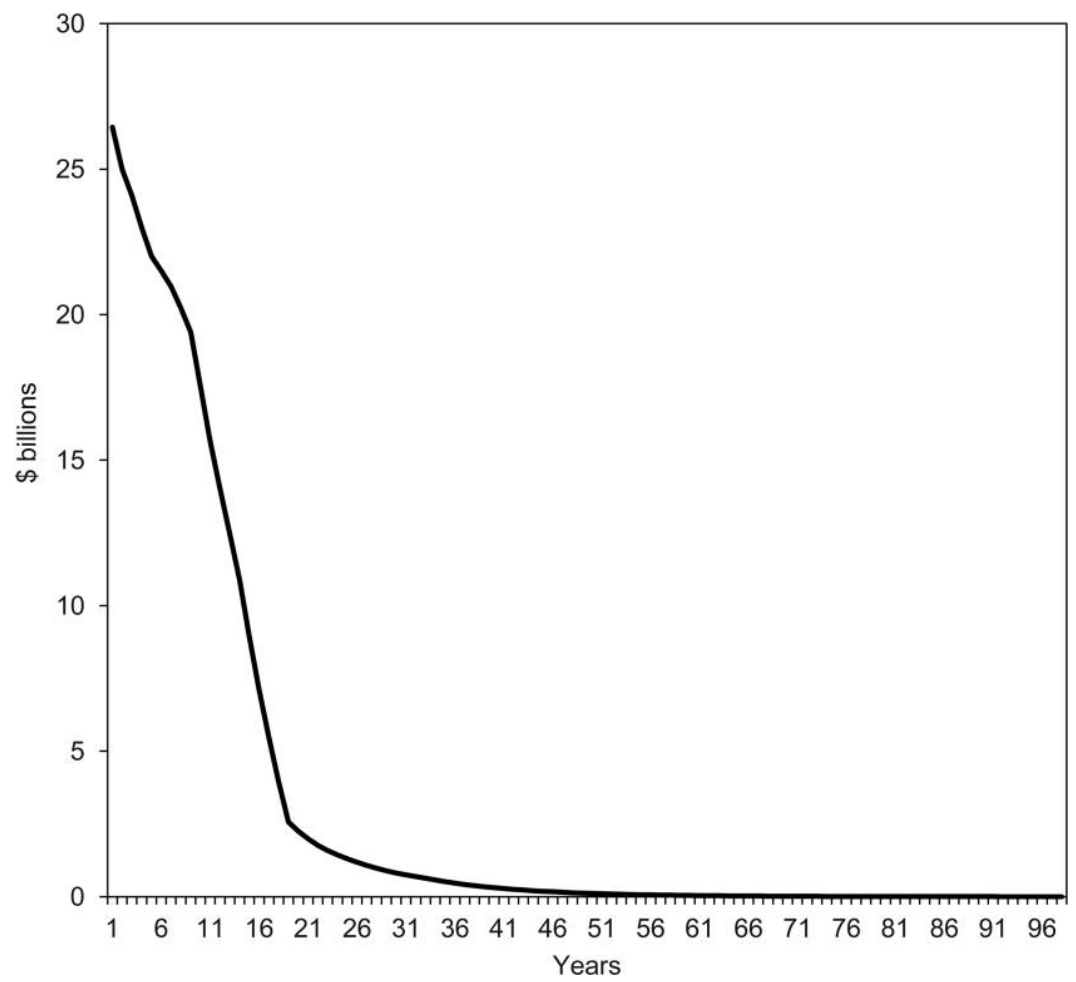

Fig. 2. Year by year discounted risk-neutral expected payouts

Notes: This graph shows the discounted risk-neutral expected payoffs by year, to illustrate the distribution over years of the PBGC's unfunded liabilities. Baseline parameters were used: $\rho$ (stocks,bonds) $=0, \kappa=0.65,90 \%$ cap. Premiums are not included, and the values in the graph reflect sample values ( $90 \%$ of the universe of total liabilities). The line was smoothed using 10-year moving averages.

The PBGC calculations project forward assets using the objective distribution of outcomes and discount them back at the risk-free rate. This procedure is not a financial valuation, because it does not reflect the fact that the worst outcomes come in the most expensive states of the world. Indeed, if assets could always be projected forward using the actual (or objective) distribution of outcomes, and discounted back to the present at risk-free rates, financial value could be created out of nowhere simply by investing in risky assets.

There are several aspects of our analysis where further research is needed to improve the calculations. First, we included no state pricing in the PBGC premiums. The financial value of the future stream of cash 
flows from these premiums may well be less than $\$ 25$ billion due to the fact that premiums are likely to be lower in exactly the states of the world where the funding status of the plans is weakened and where bankruptcy is more likely. Second, having plan-by-plan information on the duration of liabilities and the percent of PBGC liabilities covered would allow more precise plan-by-plan estimates and avoid the need for parametric assumptions on the entire sample.

Finally, and perhaps most importantly, there are critical correlations that the closed-form solution approach is unable to model. Most importantly, we have assumed that the evolution of the funding ratio and the default event are uncorrelated. However, in bad economic times, such as the recent financial crisis, plan defaults becomes more likely, interest rates are likely to drop leading to higher levels of the liabilities, and stock markets lose a substantial fraction of their value. This type of correlation can lead to a substantially higher value of the PBGC's insurance.

The fact that these correlations are almost certainly present in the underlying economics of the pension plans, but are not modeled in our exercise, strongly suggests that our figures here are a lower bound on the present value of the PBGC's unfunded liabilities. To model the correlations would require simulation (Monte Carlo) analysis, done in such a way as to be consistent with the principles of options pricing. Specifically, the Monte Carlo would require the projection of assets forward at the risk-neutral distribution of outcomes, whose mean is the risk-free rate, while also retaining the other features we have modeled using the closed form options pricing formulas. Monte Carlo simulation also allows one to take into account (1) a stochastic path of interest rates, (2) the above mentioned correlation between default and the evolution of the plans' funding ratios, and (3) the above mentioned time-varying correlation between stocks and bonds.

The development of such a simulation analysis is an important step for future research. It would begin with Monte Carlo analysis that replicated the closed form solutions presented here, and then would add the correlations to improve the accuracy of the calculations.

\section{Endnotes}

This research was supported by the US Social Security Administration through grant \#5RRC08098400-05-00 to the National Bureau of Economic Research as part of the SSA Retirement Research Consortium. The findings and conclusions expressed are solely those of the authors and do not represent the views of SSA, any agency of the federal government, or the NBER. For acknowledgments, sources of research support, and dis- 
closure of the authors' material financial relationships, if any, please see http://www .nber.org/chapters/c13053.ack.

1. The defeasance value is the cost of providing collateral that defeats the liability without paying it off, because the collateral generates income sufficient to make all required future liability payments.

2. Here, $\alpha=12.54, \beta_{1}=0.88(0.45), \beta_{2}=5.96(0.58), \beta_{3}=-0.50(0.10), R^{2}=15.9 \%$.

3 . For one plan, there was not enough information to complete the imputation.

4. Specifically, the vector of zero coupon bond price maturing at every six months out to 30 years is given by $\mathbf{B}=(\mathbf{I}+\mathbf{r})^{-1} 1$, where $\mathbf{I}$ is the identity matrix, $\mathbf{r}$ is a lower triangular matrix whose rows correspond to the par yields at each maturity (interpolated where missing), and $\mathbf{1}$ is a vector of ones. We assume the yield curve is flat after 30 years.

5. Specifically, $(15-12) *(6.6 \%-3.3 \%)=10 \%$.

6. Here, $\$ 1.949$ trillion in universe assets is derived as ( $\$ 1.754$ trillion sample assets / 0.9 ), where the assumption is that the funding ratio of the remaining $10 \%$ of the universe is the same as the $90 \%$ sample.

7. Here, $7 \%=\$ 118.6$ billion $/ \$ 1.638$ trillion and 32\% $=\$ 118.6$ billion $/ \$ 369$ trillion.

8. Here, $11 \%=\$ 358$ billion insurance value / $\$ 3.215$ trillion total liabilities. Also, $28 \%$ $=\$ 358$ billion insurance value $/ \$ 3.215$ trillion total liabilities.

9. That said, contributions are likely to be low if the sponsor is about to default. This will make the relationship between funding status and contributions nonmonotonic.

\section{References}

Brown, Jeffrey R. 2008. “Guaranteed Trouble: The Economic Effects of the Pension Benefit Guarantee Corporation." Iournal of Economic Perspectives 22 (1): 177-98.

Cox, John, Stephen A. Ross, and Mark Rubinstein. 1979. “Option Pricing: A Simplified Approach." Iournal of Financial Economics 7:229-63.

Graham, John, and Campbell Harvey. 2013. "The Equity Risk Premium in 2013." http://papers.ssrn.com/sol3/papers.cfm?abstract_id=2206538.

Kiska, Wendy, Deborah Lucas, and Marvin Phaup. 2005. "The Risk Exposure of the Pension Benefit Guaranty Corporation." CBO Paper. http://www.cbo .gov/sites/default/files/cbofiles/ftpdocs/66xx/doc6646/09-15-pbgc.pdf.

Marcus, Alan. 1987. "Corporate Pension Policy and the Value of PBGC Insurance." In Issues in Pension Economics, edited by Zvi Bodie, John B. Shoven, and David Wise, 49-80. Chicago: University of Chicago Press.

McDonald, Robert. 2003. Derivatives Markets. New York: Addison Wesley.

Merton, Robert C. 1977. "An Analytic Derivation of the Cost of Deposit Insurance and Loan Guarantees: An Application of Modern Option Pricing Theory." Iournal of Banking and Finance 1:3-11.

Moody's. 2008. "Corporate Default and Recovery Rates, 1920-2007." Moody's Investors Service Special Comment. www.moodys.com/sites/products/ DefaultResearch/2007000000474979.pdf.

Pennnacchi, George G., and Christopher M. Lewis. 1994. "The Value of Pension Benefit Guaranty Corporation Insurance." Journal of Money, Credit and Banking 26(3).

Sharpe, William F. 1976. "Corporate Pension Funding Policy." Iournal of Financial Economics 3:183-93.

Treynor, Jack L. 1977. "The Principles of Corporate Pension Finance." Iournal of Finance 32 (2): 627-38. 